\title{
O Trabalho e o Acesso ao Rendimento entre os Ciganos Virtualidades e Limitações das Leituras da Noção de Exclusão Social na Compreensão da Situação dos Ciganos
}

Sofia Delgado Marques*

\begin{abstract}
$\mathrm{R}$ mercado de trabalho bem como sobre a participação dos ciganos nos sistemas que nas sociedades modernas lhes estão associados - sistema de qualificação, sistema de protecção social - a partir da análise de um conjunto de entrevistas realizadas em espaços desqualificados nalgumas cidades portuguesas (Lisboa, Porto, Braga e Évora), bem como a representantes institucionais relevantes e a técnicos com trabalho no terreno junto desta população. Tomando por quadro de referência, as formulações que tem conhecido a noção de exclusão, são aqui equacionadas as suas possibilidades de leitura para compreender a situação dos ciganos, questionando igualmente as limitações destas leituras como matrizes de criação de políticas e práticas de inserção. Esta reflexão desenvolve-se em torno dos discursos dos ciganos procurando dar conta das dinâmicas de transformação que este grupo atravessa, também por força dos efeitos das políticas e medidas sociais.
\end{abstract}

Palavras-chave: ciganos; habitus cigano; exclusão; acesso ao rendimento; formação; políticas de inserção.

Tendo por base a noção de exclusão social, procurar-se-á reflectir neste artigo ${ }^{1}$ sobre a situação dos ciganos caracterizando a sua relação particular com a actividade económica, com a protecção social e a forma como ela contribui para configurar as relações familiares e a própria matriz de disposições subjectivas e de práticas face a estas esferas de participação. Simultaneamente discute-se as virtualidades desta noção e das suas diversas leituras enquanto chave de interpretação das realidades que se procura compreender e como pressupostos subjacentes a medidas, políticas e intervenções que se têm dirigido à inversão das situações de pobreza e exclusão em que vive parte importante dos ciganos. Esta discussão tem desde logo como elementos de referência por um lado, as questões que se colocam à aplicação deste conceito no quadro da sociedade portuguesa e por outro lado, as virtualidades e limitações teóricas que se colocam à utilização das diferentes leituras da exclusão social na análise da situação da população cigana $^{2}$.

\footnotetext{
* Socióloga. Técnica Superior no Instituto de Segurança Social, I. P. Contacto: sofiamarques71@gmail.com

- presente texto baseia-se num dos capítulos do Relatório Final do estudo "A Comunidade Cigana em Portugal - Representaçes e Dinâmicas de Exclusāo/Integraçāo", coordenado pelo Doutor Eduardo Costa Dias e financiado pela Fundaçāo para a Ciência e Tecnologia. Este estudo que teve como entidade proponente o Centro de Investigação e Estudos de Sociologia (CIES) e teve como entidade parceiras a Rede Europeia Anti-Pobreza (REAPN/Portugal), o Secretariado Diocesano para a Pastoral dos Ciganos, o Programa de Promoçāo Social dos Ciganos. De entre a equipa de investigadores em que participou a autora foram responsáveis pela realizaçāo das entrevistas Nuno Valente (CIES/ISCTE) e Isabel Alves (REAPN/Portugal) tendo contado com o apoio no terreno das entidades parceiras no estudo:

${ }^{2}$ Agradece-se o comentário do Professor Doutor Luís Capucha a este texto, sendo contudo da nossa responsabilidade todas as conclusøes que aqui se apresentam.
} 


\section{Breves considerações sobre o conceito de exclusão social e as suas virtualidades na análise da situação portuguesa}

\section{Exclusão social, um conceito e as suas circunstâncias}

O surgimento e difusão da noção de exclusão social, é sabido, teve na sua base razões que não corresponderam num primeiro momento à generalização de uma perspectiva teórica consolidada, tendo ao contrário a discussão conceptual surgido numa fase posterior à da difusão do uso da expressão. De facto, como aponta Paugam (1996) a expressão teria sido escolhida com base em critérios editoriais já depois da redacção da obra de René Lenoir, Les Exclus, un Français sur Dix, (1974) $)^{3} \mathrm{e}$ aparece um reduzido número de vezes no texto daquele que é por vezes apontado como o seu "documento fundador". Por outro lado, Bergham (1995) sugere que a sua apropriação em sede das discussões desenvolvidas na ainda $\mathrm{CE}$, factor de impulsionamento evidente da difusão do termo, teria surgido como reacção de alguns governos, hostis à aplicação das expressões "pobreza" ou "desfavorecimento" à realidade social dos seus países. O desenvolvimento das discussões em torno da conceptualização e operacionalização desta noção fez-se assim de forma muito referenciada aos contextos políticos em que foi apropriada (Bergham, 1995), mantendo-se não só as divergências sobre os seus contornos, como uma relativa imprecisão quanto ao seu significado em resultado da apropriação do termo pelos media e de uma maneira geral pelo senso comum ${ }^{5}$.

De qualquer modo, o conceito mantém uma validade reconhecida quer do ponto de vista teórico, quer do ponto de vista normativo, isto é, ao nível das políticas e das intervenções que visam o combate aos fenómenos que designa. Esta valida- de advém do facto de trazer para a análise questões que a noção de pobreza não incorpora. Resumidamente essas dimensões dizem respeito à multidimensionalidade, que é possível introduzir na análise das situações ${ }^{6}$ por contraponto com a noção de pobreza que se referencia apenas às condições de vida e de consumo dos indivíduos e das famílias (Bergham, 1995). Por outro lado, este conceito permite ainda dar relevo aos processos por contraposição ao conceito de pobreza que daria conta de resultados (Bruto da Costa et al., 1994). A ênfase nos processos também desloca algumas questões, interpelando as sociedades e os seus modos de funcionamento enquanto o conceito de pobreza se centra fundamentalmente nos que vivenciam as situações.

Contudo, é justamente a referenciação a contextos particulares que está na base das divergências na leitura do conceito. Basicamente poderíamos resumir as diferentes posições, associando-as por um lado, ao contexto francófono em que a exclusão é entendida fundamentalmente como a quebra do laço social, estruturado em função de um modelo de sociedade salarial onde o trabalho e sobretudo, o emprego assalariado a que se associa um conjunto de direitos ao nível da protecção social, assume uma forte centralidade na estruturação das relações sociais. E por outro lado, constituiu-se uma leitura de raiz anglófona que perspectiva a exclusão por relação com o corpo de direitos consagrados e, como tal, postula a exclusão em função dos obstáculos que se colocam ao acesso à cidadania. Na primeira leitura, as formas de solidariedade orgânica estão muito associadas à divisão social do trabalho e é em função desta grelha de leitura que são colocadas as questões culturais, simbólicas e identitárias criadas como consequência da "crise do laço social" decorrente das transformações no mercado de emprego, na divisão internacional do trabalho, nos modelos demográficos que puseram em causa uma forma de organização das

\footnotetext{
${ }^{3}$ Paugam nota que a expressão teria na realidade, aparecido há dez anos proposta pelo Secretário-geral do plano francês, Pierre Massé e num outro documento intitulado "L'Exclusion Sociale" e publicado no âmbito do movimento ATD - Quart Monde (Klanfer, 1965 cit. por Paugam, 1996).

4 No texto em inglês utiliza-se o termo "least privileged" pelo que a tradução é nossa.

${ }^{5}$ Esta amplitude semântica leva mesmo a que alguns autores contestem mesmo a possibilidade de conferir a este termo o estatuto de conceito teórico.

6 Trata-se aqui de considerar não só a perspectiva de acesso a bens e condições de vida, mas da relação com os grandes sistemas sociais, o mercado de trabalho que promove não só o acesso ao rendimento, mas a integração social, o sistema democrático e legal que promove a integração cívica, o sistema de protecção social que promove a integração social e a família e comunidade que promovem a integração interpessoal (Commins, 1993 cit. por Bergham, 1995).
} 
sociedades que tinha marcado os golden thirties nos países da Europa central.

Na segunda leitura de referenciação, a ideia da exclusão social reporta-se a noções de participação ou de afastamento relativamente a um conjunto de direitos consagrados (civis, políticos e sociais) que são a expressão de consensos em cada uma das sociedades por relação às quais estas noções se equacionam. Nesta acepção considera-se a cidadania (Bergham, 1995; Room et al., 1992) como a norma de referência para entender as situações de exclusão social e de integração.

Esta divergência entre concepções de base reflecte-se como veremos nas políticas e práticas que incidem sobre o acesso ao rendimento como via de inversão das situações de exclusão social. É justamente porque se entende que estas visões actuam muitas vezes como pressupostos de políticas e práticas por parte dos agentes que têm a seu cargo a intervenção, que nos parece importante confrontar as diferentes leituras com as possibilidades de interpretação da realidade que elas oferecem e também nesta medida com as possibilidades de eficácia da intervenção.

\section{Pobreza e exclusão social: desfasamentos de leitura colocados pela realidade portuguesa}

Não constituindo um sinónimo, a noção de exclusão social tem uma relação com a noção de pobreza $^{7}$ que não pode deixar de se reportar aos processos de desenvolvimento das sociedades. Nos países de desenvolvimento intermédio como Portugal, pode ser-se pobre sem se estar excluído dos principais sistemas sociais e pode estar-se excluído designadamente, do mercado de trabalho formal e não se ser pobre se se recorrer aos expedientes da economia informal, da economia subterrânea, etc. (Capucha, 1998b) $^{8}$.
Para entender a situação dos ciganos em Portugal, enquanto minoria sujeita a processos de ausência de participação nas esferas que são determinantes para a integração na nossa sociedade e protagonista de mecanismos de auto-fechamento, potencialmente conducentes a situações de pobreza e exclusão social será pois, importante reter a especificidade da concretização do Estado Providência. De uma forma geral, torna-se ainda necessário considerar o modelo de desenvolvimento da sociedade portuguesa no que diz respeito aos modelos de trabalho assalariado, de organização da família, etc.

O Estado Providência em Portugal constitui-se quando noutros países já estava a sofrer uma crise que iria conduzir ao questionamento e posterior "recalibragem" das suas modalidades de organização. Ainda que o seu desenho institucional e jurídico seja idêntico ao de outros países europeus que adoptaram o modelo universalista, existem grandes debilidades ao nível do montante das prestações e da distância entre os sistemas de protecção e os potenciais beneficiários ${ }^{9}$.

A incompletude de um projecto de sociedade que em parte dos países europeus, correspondeu à criação do Estado Providência é, ainda, bem patente se se considerar o conjunto das "políticas de integração"10 (Castel, 1998). Os fracos níveis de escolarização e de qualificação profissional do nosso país, a persistência de situações de habitação precária, as debilidades ao nível da cobertura das políticas de saúde são também a marca de um projecto de sociedade que está bem longe de corresponder ao modelo conseguido por esses mesmos países. Desta forma, um número importante de portugueses cujas qualificações são baixas e muitas vezes inferiores ao ensino básico, estão desde logo impossibilitados de aceder às oportunidades de emprego nos sectores mais bem remunerados, mais estáveis e mais beneficiados no que

\footnotetext{
${ }^{7}$ Entende-se pobreza no sentido de escassez de recursos materiais para suprir as necessidades individuais e familiares, podendo ser absoluta no caso de privar as pessoas dos recursos que lhes permitam a "eficiência física" ou relativa em situações em que as pessoas estejam abaixo de um limiar que corresponde à norma dos países em que vivem (Capucha et al., 1998b).

${ }^{8}$ Assim, se nos países mais desenvolvidos a população pobre - isto é, aquela que vive em situações de escassez de recursos materiais, sociais e culturais - coincide tendencialmente com as categorias excluídas, nos países subdesenvolvidos, onde coexistem elites cujas condições de vida contrastam com uma massa de pessoas na pobreza mais extrema, não se pode falar de exclusão (Capucha, 1998b).

9 Esta distância é traduzida em situações de ausência de reclamação dos próprios direitos pelos potenciais beneficiários, realidade que ficou bem patente no período de introdução do Rendimento Mínimo Garantido (Capucha, 1998a).

${ }^{10}$ Castel (1998) refere-se às políticas de integração entendidas como a "busca de grandes equilíbrios pela homogeneização da sociedade a partir do centro (...) desenvolvidas através de directrizes gerais num quadro nacional [como as] medidas que visam promover o acesso de todos aos serviços públicos e à instrução (...) o desenvolvimento das proteç̧ões e a consolidação da condição salarial".
} 
diz respeito aos mecanismos de protecção social. Deste ponto de vista, a situação problemática da população cigana, não obstante as vulnerabilidades acrescidas deste grupo e ainda que os estudos não sejam ainda muito abundantes tem de ser percepcionada num quadro mais vasto.

A participação no mercado de trabalho e nos esquemas de protecção social não são garante por si só do acesso a um nível de vida compatível com os padrões que são mantidos na nossa sociedade. A insuficiência da realização de um Estado Providência é ilustrada pela fragilidade da posição social dos trabalhadores de baixos salários ou a condição dos pensionistas (Albuquerque et al., 2001, Albuquerque et al., 2002) ou ainda pelo recurso de uma parte importante da população, a actividades exercidas numa base de pluriactividade ${ }^{11}$, à margem do mercado formal de emprego ou mesmo num quadro de "economia da delinquência" em complemento de pensões ou a baixas remunerações, como acontece com os ciganos (Mendes, 2005).

Por outro lado, a utilização do conceito de exclusão social sobretudo se partirmos de uma leitura de natureza francófona, supõe um padrão de valores, normas e expectativas partilhado, a partir do qual ele se joga. Este pressuposto de generalização de expectativas é justamente um a priori que se torna discutível quando se trata de comunidades ${ }^{12}$ cujos modos de vida contrastam com tais modelos, como as comunidades ciganas. Reflectir sobre este contraste não significa reificá-lo ignorando o papel de homogeneização tendencial de disposições subjectivas que têm a escolarização, os meios de comunicação social e o próprio trabalho das instituições no terreno, bem como as importantes transformações que tem vindo a sofrer o modo de vida itinerante com as consequentes implicações em todos os níveis da existência das comunidades ciganas (Castro, 1995).

\section{Os ciganos e o acesso ao rendimento}

Analisando os dados relativos ao grupo de ciganos inquirido para a realização deste estudo ${ }^{13}$, e mais concretamente nos casos que configuram situações mais conformes aos modelos de acesso ao rendimento preconizada pelo modelo de sociedade salarial - os empregados e os pensionistas são evidentes as situações de complemento de rendimento.

Quadro 1 - Meios de vida e condição perante o trabalho dos ciganos entrevistados

\begin{tabular}{|c|c|c|c|c|c|c|c|c|}
\hline \multirow{2}{*}{ Meios de vida e condição perante o trabalho } & \multicolumn{3}{|c|}{ Entrevistados } & \multicolumn{4}{|c|}{ Familiares referenciados } & \multirow[t]{2}{*}{ Total } \\
\hline & F & M & Total & $\mathrm{F}$ & M & $\mathrm{S} / \mathrm{R}$ & Total & \\
\hline 1. Pensões & 2 & 1 & 3 & 1 & 1 & & 2 & 5 \\
\hline 2. Desempregado & - & - & - & - & - & & - & \\
\hline 3. Doméstica e pensões & - & - & - & 2 & - & & 2 & 2 \\
\hline 4. Exclusivamente doméstica & 3 & - & 3 & 1 & - & & 1 & 4 \\
\hline 5. Exclusivamente vendedor ambulante & 6 & 1 & 7 & - & - & 1 & 1 & 8 \\
\hline 6. Prestação e venda ambulante & 3 & 1 & 4 & 1 & 1 & & 2 & 6 \\
\hline 7. Venda e doméstica & - & - & - & 2 & - & & 2 & 2 \\
\hline 8. Venda e profissão assalariada & - & 3 & 3 & - & - & & - & 3 \\
\hline 9. Exclusivamente profissão assalariada & - & - & - & - & - & & - & - \\
\hline 10. Indivíduos com outra profissão (não especificada) & - & - & - & 1 & 3 & & 4 & 4 \\
\hline TOTAL & 14 & 6 & 20 & 8 & 5 & 1 & 14 & 34 \\
\hline
\end{tabular}

Fonte: Dados recolhidos em entrevistas à população cigana, CIES/REAPN/Portugal.

\footnotetext{
${ }^{11}$ Os exemplos mais estudados são os dos operários industriais a praticar a agricultura a tempo parcial, mas o plurirendimento e a pluriactividade exercida em esferas mais ou menos informais, são recorrentes noutros grupos profissionais.

12 Quando utilizamos o termo comunidades queremos por um lado, evidenciar alguns atributos da organização social destes grupos ainda muito marcados por formas de solidariedade mecânica, baseadas no parentesco, demarcando-nos de uma linguagem de matriz multiculturalista e da "leitura homogeneizante" que lhe está associada (Machado; 1999).

${ }^{13}$ Foram abordadas 20 famílias de ciganos residentes em diferentes contextos do país: Lisboa (Bairro da Buraca e Casalinho da Ajuda, Rio Seco), Porto (Bairro de Aldoar, S. João de Deus e da Biquinha), Évora e Braga (Vila Verde), tendo o trabalho de campo sido realizado durante o ano 2000.
} 
Das poucas situações de emprego assalariado detectadas nas entrevistas e para as quais se dispõe de informações mais seguras (apenas três) em todas se praticava em complemento a venda ambulante. Nos casos de pessoas que recebem prestações - 13 das situações referenciadas em entrevista - seis delas declararam manter a venda como fonte de rendimento ${ }^{14}$, sendo recorrentes as referências à insuficiência dos montantes dessas prestações para fazer face às despesas básicas.

“Não dá, porque pagar luz, água, telefone, calçar e vestir tantos filhos, onde é que isto dá? Não dá!" (Bairro de Aldoar, Porto).

“Uma ajuda, não é mais nada, (...) não me chega para os medicamentos (...) vou três vezes, quatro vezes por mês [à farmácia]. (...)" (Bairro da Biquinha, Matosinhos).

As situações mencionadas confirmam um dado já conhecido, que torna evidente a necessidade de questionar a capacidade de integração do mercado de emprego e do sistema de protecção social português como via sustentável de protecção contra as situações de pobreza, já que estes não garantem por si só e segundo os moldes em que funcionam neste momento, a viabilidade de projectos de autonomia e de acesso a um padrão de rendimento que assegure as condições de vida aceites pela generalidade da sociedade portuguesa ou mesmo por vezes, mínimos de sobrevivência.

Evidências dos efeitos de um atraso estrutural da população cigana são os baixíssimos níveis de escolaridade que esta apresenta, com efeitos visíveis nas novas gerações, mais escolarizadas é certo, mas ainda muito marcadas pelo abandono escolar, agravado nas raparigas (Dias et al., 2001). Esta desvantagem tem por si só, repercussões nas possibilidades de entrada no mercado de trabalho, mas dificulta igualmente, o acesso à qualificação profissional que exige geralmente, a escolaridade básica.

Tal é muito patente no grupo de ciganos entrevistados, dos quais apenas dois em vinte mencionavam ter frequentado cursos de formação profissional, havendo ainda três referências indirectas a familiares que o teriam feito. Confirmam-se, as- sim, informações recolhidas por outros estudos realizados, como o do Secretariado Diocesano para a Pastoral dos Ciganos, em 1994, segundo o qual apenas $2,5 \%$ da população cigana inquirida com mais de 16 anos, tinha frequentado cursos de formação profissional (Marques et al., 1997).

A tentativa de colocar a situação dos ciganos em perspectiva, dando conta das problemáticas que se colocam para uma significativa parte importante do tecido social português, designadamente as pessoas e famílias mais empobrecidas, não pode obscurecer questões adicionais que se relacionam directamente com as características desta população ao nível dos seus modos de organização familiar e com os seus quadros mentais.

\section{Particularidades culturais: fechamento e reificação de fronteiras}

O segundo foco de questões que se coloca ao reflectir sobre a situação dos ciganos face ao trabalho e ao acesso ao rendimento do ponto de vista da noção de exclusão social, reside na dificuldade adicional de pensar em grupos para os quais, social e culturalmente, o acesso ao rendimento não passa pelas formas institucionais por que se pauta tradicionalmente o emprego. Os grupos ciganos tendencialmente organizam-se para suprir as necessidades ao nível da protecção social, de forma autónoma e mais ou menos eficaz, e sustentam a sua identidade pessoal e social, em bases bem distintas das do cidadão que interiorizou há muito o modelo da sociedade salarial.

É com alguma reserva que se pode pensar a situação dos ciganos enquanto excluídos se se associar essa exclusão ao mercado de emprego. Não faz aqui muito sentido referenciar os "normais inúteis" de Donzelot (1994), nem uma "crise do laço social" criada com o afastamento do mercado de trabalho, pois estamos perante grupos que tendencialmente manifestam uma forte coesão interna $^{15}$ que desenvolvem na sua grande maioria, actividades económicas não integradas no mercado formal de emprego.

\footnotetext{
${ }^{14}$ Note-se que em nenhuma das situações de acumulação de rendimentos identificadas se incluíam beneficiários do Rendimento Mínimo Garantido, situação em que o exercício de uma actividade remunerada e o benefício da prestação é previsto, nos casos em que o rendimento per capita no agregado familiar não atinja um valor equiparado ao valor da pensão social.

15 Ao longo das entrevistas foram não obstante surgindo indícios de ruptura dessa coesão interna das comunidades ciganas que eram atribuídos ao envolvimento dos ciganos no tráfico e consumo de droga entre as gerações mais jovens.
} 
É aqui que se jogam as questões subjectivas e culturais da problemática da integração social dos ciganos supondo que se analise a vertente activa e significativa destes processos, isto é, que se dê relevo aos universos simbólicos dos actores e às suas formas particulares de organização social.

Mais do que factores de exclusão resultantes de um deficit ao nível dos requisitos para aceder às oportunidades que a sociedade oferece (por distância face à informação, por incapacidade de formular projectos de transformação do próprio destino, por inadequação da vivência e gestão do tempo e dos recursos, por baixa auto-estima, por ausência de hábitos de trabalho regular, etc.), trata-se de formas de organização interna dos grupos sociais, "modos de vida" contrastantes com os propostos pelo padrão vigente nas sociedades modernas ocidentais.

Não se nega que os ciganos possam apresentar alguns handicaps de inserção, contudo, caracterizar apenas as "ausências" que a socialização das comunidades ciganas apresenta face a um modelo adequado à detenção de requisitos para aceder a um emprego significa omitir que existem modelos de organização específicos das populações ciganas com respostas próprias e diferenciadas às questões do acesso ao rendimento e quadros mentais correspondentes. Tal não significa adoptar uma perspectiva multiculturalista, reificadora de traços culturais e disposições subjectivas que são dinâmicos e permeáveis, mas tão só uma análise compreensiva no sentido weberiano que forneça um quadro abrangente de interpretação das situações.

\section{O lugar do trabalho nos modos de vida dos ciganos}

A descoincidência entre o modelo da sociedade salarial e os modos de vida de grande parte das comunidades ciganas repercute-se por um lado, no tipo de actividades económicas em que prepondera uma tradição de trabalho independente. Uma análise das práticas económicas da população entrevistada permite constatar que, tal como têm demonstrado outros estudos, a venda prevalece como principal fonte de rendimento nestas comunidades. Assim, a nossa recolha permitiu concluir que 19 em 23 situações de activos referenciadas, esta era a actividade exercida, em onze casos paralelamente com outras actividades ou fontes de rendimento e em 8 casos em exclusividade. Tal como acontece com outros grupos na sociedade portuguesa, a pluriactividade e o plurirendimento é para os ciganos, uma estratégia para obter rendimentos mais elevados.

A versatilidade nas actividades económicas e a mobilidade espacial que estão associadas às modalidades em que é exercida a venda, têm vindo a ser explicadas por alguns autores como o resultado de constrangimentos seculares que forçaram a itinerância dos ciganos. Para outros autores como Okely (1983), a opção por este tipo de actividades e pela mobilidade que lhes está associada, justifica-se como resistência à proletarização e alienação associadas aos vínculos salariais.

Como face a qualquer outro traço cultural, afirmar uma resistência voluntarista, seria tão redutor como considerar apenas, a sua componente estrutural e histórica. Independentemente da sua prática poder ser atribuída a constrangimentos históricos, ou a qualquer "desejo" intrínseco de liberdade $^{16}$, é relativamente consensual o reconhecimento de que a venda e o comércio de forma geral, têm vindo a ser relacionados com a possibilidade de um estilo de vida autónomo e itinerante. Formoso (1986 cit. por Castro, 1995) refere-se a habitus de grupo étnico que estruturaria o modo de vida caracterizado pela itinerância de grande parte dos ciganos, estruturaria ainda as suas práticas quotidianas e as opções inerentes enquanto sistema de disposições incorporadas, duráveis e transponíveis, capaz de orientar de uma maneira geral, as escolhas individuais em situações objectivas que asseguram a sua reprodução, num processo que passa de geração em geração (Bourdieu, 1979).

Liégeois refere-se a um "estado psicológico" com um papel económico e social, mais do que uma prática com uma base material. À itinerância estaria associado um conjunto de valores que

\footnotetext{
${ }^{16}$ Os trabalhos sobre ciganos têm vindo a ser marcados por uma importante componente mistificadora que ao denunciar o estereótipo negativo generalizado, acaba por construir um discurso apologético em torno de um sentido de liberdade, de uma disposição festiva que acaba por obscurecer mais do que esclarecer o conhecimento sobre os ciganos. Este tipo de discurso acaba por não fazer mais que reproduzir a própria cosmogonia que Luc de Heush (1965) encontrou no curso da sua pesquisa e que Castro (1994) recolhe no seu trabalho.
} 
prefigurariam uma espécie de "código de honra" em que se valoriza o trabalho por conta própria, a autonomia, a manutenção da independência económica. Segundo Liégeois, "Se é uma honra ser associado, seria uma vergonha ser empregado e não existem relações salariais (excepto casos novos e raríssimos) entre ciganos." (1989: 74).

Por outro lado, é bem diversa a relação com o trabalho do ponto de vista da construção da identidade social e pessoal e ainda segundo Liégeois, o trabalho é "concebido como uma necessidade, não um fim e deve deixar o homem livre para se ocupar das questões sociais (reuniões, visitas de famílias, recepções, visitas a doentes, etc.) e para desenvolver as suas relações (...) um dos elementos mais marcantes [d]a identidade do cigano e itinerante (...) suporte da [sua] conservação" (1989:72). Mendes, refere-se também à secundarização do trabalho na escala de valores "O trabalho não é um valor ou um aspecto da vida em que se pode obter realização pessoal, mas uma condição indispensável à sobrevivência quotidiana" (2005:123).

A intrincada relação, entre economia e organização social destas comunidades, entre os mecanismos de solidariedade familiar e a capacidade de adaptação do ponto de vista das actividades económicas, modifica a relação objectiva e subjectiva que os indivíduos estabelecem com as formas de acesso ao rendimento, transformando o quadro simbólico que caracteriza as situações de exclusão, designadamente aquele que diz respeito à percepção da vulnerabilidade ao desemprego. Como aponta Mendes, "o conceito de trabalho socialmente construído deriva, e é fortemente determinado, pelas características da sua própria organização social, que se fundam na família extensa." (2005:).

É sugestiva a situação relativamente à categoria "desempregado" que não tem qualquer expressão nas situações identificadas nas vinte entrevistas efectuadas (cf. Quadro 1) ainda que tivessem sido realizadas com habitantes de bairros empobrecidos e problemáticos do ponto de vista da concentração das situações de vulnerabilidade social. Esta categoria social invocada como uma das vítimas por excelência das situações de exclusão não parece pertinente na linguagem dos ciganos entrevistados, justamente porque ela supõe uma expectativa de emprego que não existe, ou pelo menos não tem existido entre esta população.

\section{Centralidade da família na protecção social entre os ciganos}

Se o acesso aos recursos económicos nas comunidades ciganas está pois, tradicionalmente estruturado em torno de modalidades distintas das criadas pelo Estado fordista, também o estão as respostas às necessidades de protecção social. Segundo Mendes (2005), a família constitui uma "unidade de cooperação" em que colaboram todos os membros, cabendo ao pai o papel redistributivo dos rendimentos em função das necessidades. A unidade familiar assume uma centralidade enquanto núcleo de tomada de decisões, gestão de recursos e de divisão de atribuições na obtenção de recursos e serviços.

Este quadro de organização da protecção social colectiva, pode explicar em parte a relação de omissão que os ciganos mantêm com o cumprimento de obrigações fiscais e de contribuição para a Segurança Social que foi testemunhada no trabalho de campo desenvolvido.

Dos catorze entrevistados que referenciaram a prática da venda, apenas quatro - menos de um terço - pagavam contribuições para a Segurança Social e somente um desses referiu declarar os seus rendimentos. Este é porventura, o outro lado de um processo de exclusão da condição de cidadania, manifesto na ausência de reconhecimento da necessidade de contribuir para o financiamento dos sistemas como contrapartida do usufruto dos seus benefícios. Mas parece denotar justamente a referida centralidade que a família assume na garantia de protecção social aos seus membros, isto é, um modelo de protecção de natureza pré-capitalista.

A este título parece-nos bastante relevante a resposta de um dos ciganos entrevistados, feirante, adulto, quando interrogado acerca do pagamento de contribuições à Segurança Social:

“Eu não, só os meus pais. (...) Não [não pago], como eu sempre ajudei os meus pais e nunca me faltou nada" (Évora).

Se se considerar uma leitura da noção de exclusão que considera não só os aspectos da questão que estão relacionados com o acesso à protecção social e ao rendimento por via do emprego, mas também a crise nos laços sociais horizontais, isto é nas solidariedades informais e sociabilidades, a que se refere Castel através da sua noção de desafiliação 
(Castel, 1998), ter-se-á com certeza, alguma dificuldade de a aplicar às comunidades ciganas.

\section{Dinâmicas de mudança nas comunidades ciganas: práticas e referências cruzadas}

\section{Acesso aos recursos e protecção social}

Posto nestes termos, encontra-se assim um conjunto de factores que evidenciam como o modelo do Estado Providência fordista tem algumas dificuldades em lidar com as questões colocadas pela permanência nos territórios nacionais de minorias etnicamente diferenciadas como são no caso os ciganos (Bjorklund, 1987). Contudo, e como têm vindo a sublinhar alguns autores portugueses há que acautelar-se de cair num pressuposto multiculturalista de reflexão sobre as identidades culturais que as considera de forma estanque e fixista (Machado, 1999; Pires, 2003).

Este pressuposto que assume que cada minoria corresponde a uma comunidade com uma cultura de fronteiras invioláveis é, no caso, contrariado em confronto com algumas práticas e discursos dos ciganos entrevistados. Nestes evidenciam-se processos de mudança cultural à medida que os contextos de socialização destas populações se vão abrindo para além das fronteiras das próprias comunidades.

Um dos casos em que as práticas se referenciam a combinações de modelos de organização social diferenciados é o da complementaridade entre rendimentos oriundos da venda e ganhos fixos provenientes de pensões. Para algumas famílias, esta segunda fonte de rendimentos funciona como uma plataforma de rendimento regular face à incerteza dos lucros da actividade da venda, que permite cobrir os encargos fixos do exercício da actividade independente num regime de legalidade.
“Tenho uma pensão de invalidez (...) e às vezes mal da gente se não fosse isso perdíamos o lugar nas vendas (...) Temos os lugares da venda, pago trinta e oito contos por mês ${ }^{17}$. Se não fosse isso, não dava. Vinte e cinco $\operatorname{contos}^{18} \mathrm{eu}$, vinte e cinco contos a mulher. (...) Cinquenta, mas tiramos trinta e oito para pagarmos os lugares." (Casalinho da Ajuda, Lisboa).

Este tipo de estratégias que incorpora benefícios do Estado Providência na viabilização de actividades exercidas por conta própria, dá conta da insuficiência dos recursos obtidos pelas vias formais, mas em muitos casos também, da insuficiência da via informal para suprir necessidades a este nível, em face da precariedade das actividades económicas dos ciganos.

Não se está pois, perante uma comunidade impermeável às dinâmicas da sociedade maioritária, mas perante estratégias de articulação de lógicas diferenciadas neste caso, em proveito da viabilização de modos de vida tradicionais. Estas estratégias traduzem formas de incorporação de modelos sociais da sociedade portuguesa que contrariam a irredutibilidade das práticas culturais. Aliás, a capacidade de recolha e difusão de informação e de reivindicação dos ciganos relativamente a apoios concedidos a populações desfavorecidas é um tópico conhecido dos técnicos que trabalham no terreno ${ }^{19}$ e de resto, bastante explorado mediática e politicamente ${ }^{20}$. Independentemente de todos os pressupostos etnocêntricos que estejam na base destas formas de exploração negativa da imagem dos ciganos, o quadro é de facto, mais complexo que a perspectiva romantizada que por vezes surge relativamente às comunidades ciganas como enclaves que se manteriam à parte da restante sociedade.

Trata-se antes de formas de racionalidade centradas num modelo de pertença que não se baseia no contrato social ou em qualquer outro modelo de cidadania, mas que está referenciado a for-

\footnotetext{
7 Cerca de $40 €$.

18 Cerca de $125 €$

${ }^{19}$ Este tipo de atitude por exemplo face à prestação do RMG (depois RSI) é registada no estudo de avaliação de impactes do Rendimento Mínimo Garantido (Guerra et al., 2002) em que a prestação é percebida pelos ciganos como um direito. Esta atitude é contrastante com a dos africanos para quem a atribuição é algo que vai para além daquilo a que teriam direito.

20 Este tipo de aproveitamento acabou por incidir sobretudo na cobertura mediática das situações de fraude relativamente ao Rendimento Mínimo Garantido e atingiram o seu culminar com afirmações do candidato do CDS/PP às eleições legislativas extraordinárias de 2001.
} 
mas de solidariedade mecânica, incorporando por vezes, e de forma muito versátil, até os argumentos de base multiculturalista que são utilizados por alguns produtores de discurso sobre ciganos ${ }^{21}$.

\section{Área profissional: aspirações expecta- tivas e projectos}

O mesmo cruzamento de referências tradicionais ciganas e da sociedade maioritária se encontra ao analisar outra das componentes estratégicas das "dinâmicas de subjectividade" (Machado, 1991) que dizem respeito aos projectos e aspirações relativamente à "venda" ao nível pessoal, face às gerações mais jovens (filhos ou netos) bem como às representações dos ciganos face à formação profissional.

A pesquisa efectuada no quadro do presente estudo, suscitou assim, alguma perplexidade evidenciada já noutras investigações (Castro, 1994; 1995), relativamente à irredutibilidade de um modo de vida cigano cuja referência matricial permitiria falar de um habitus cigano.

Tal reserva não significa a negação da persistência de modos de vida específicos, como aliás, foi referido noutro momento deste texto. De facto, o modo de vida cigano parece intrinsecamente associado à venda ambulante, constituindo uma plataforma de referência nas disposições dos ciganos, que serve mesmo para compreender as transformações que se vão dando.

"nós já crescemos a vender, aquilo está no nosso sangue, se me perguntar 'queres um lugar fixo a ganhar 200 contos $^{22}$ ou estar numa banca a ganhar 100 contos $^{23}$ ?', preferimos estar numa banca. Nasce connosco." (Bairro da Buraca, Lisboa)

“(...) os ciganos vivem do vender. Já tem muitos anos, o cigano compra e vende. Há quem trabalhe na construção civil, os rapazes, marceneiros, algumas de nós são mulheres-a-dias, mas antigamente não, era mais a venda." (Rio Seco, Lisboa).
"Bem, há ciganos agora que até trabalham... (...) o meu filho (...) tirou dois cursos (...) mas o meu filho diz que quer trabalhar, que se arranjasse emprego... mas os ciganos é só feirantes. Acho que o cigano nasceu para isso, pronto, para feirantes. (...) Não [não é porque não haja outras hipóteses], gostamos. “(...) Porque os ciganos... é só mesmo para a feira" (Bairro S. João de Deus, Porto).

"A vida dos ciganos é esta, nem todos os ciganos, alguns ciganos têm trabalho próprio" (Prado, Braga)

Se as rápidas transformações que têm vivido as sociedades modernas, e em especial a sociedade portuguesa nos últimos quinze anos, podem explicar esta transformação que se vai operando, o próprio reforço das políticas sociais e a implementação do Rendimento Mínimo Garantido teve um papel que adquire uma especial visibilidade no discurso dos próprios ciganos.

"Os ciganos não gostam de ser mandados. 'Pá, vai para aqui, tu vem para aqui', isso confunde-os. (...) [Agora há] Mais ciganos a trabalharem por conta de outrem por causa, se calhar, da evolução do Rendimento Mínimo, de 'acordarem' e disseram 'fazer mais alguma coisa que só a venda não dá!'." (Bairro das Galinheiras, Lisboa).

"O modo de vida do cigano é a venda. (...) Agora o Rendimento Mínimo acho que anda a mandar trabalhar." (Bairro das Galinheiras, Lisboa).

As posições expressas relativamente à formação profissional são também relevantes do ponto de vista da compreensão da dimensão avaliativa dos ciganos em relação à sua actividade e às perspectivas de futuro, permitindo assim, retirar algumas conclusões relativamente às formas de representar os percursos profissionais e de uma forma geral os modos de vida dos ciganos enquanto entidade colectiva.

\footnotetext{
${ }^{21}$ Guerra et al. (2002) referem que para os ciganos o RMG surge como "medida reparadora da discriminação cultural que sempre consideraram existir para com a sua etnia ou comunidade, e o Estado português não faz mais do que a sua obrigação em sustentar uma situação para a qual não vêem saída".

${ }^{22}$ Cerca de $1000 €$.

23 Cerca de $500 €$.
} 
“...darem cursos para o futuro para ver se não vão só para mercados" (Bairro da Cruz da Picada, Évora).

"Eu acho que sim [que se deveriam promover cursos de formação noutras áreas], porque se um dia mais tarde, se acabassem [as feiras], já tínhamos alguma profissão, alguma coisa que nós soubéssemos fazer para seguir para a frente, depois para não estarmos a começar de novo, assim para começar já tínhamos outra coisa." (Bairro da Cruz da Picada, Évora).

"Acho que a nível da formação deveriam desenvolver-se cursos para estas crianças poderem trabalhar." (Rio Seco, Lisboa)

"Para tirar e eu penso que é importante se o cigano quer ser alguém no futuro e é por aí que tem de começar, não é? Porque não vai ser só pelas feiras, as feiras estão a acabar isso é óbvio vão acabar e os cursos... podem fazer com que os ciganos frequentem os cursos para tirarem uma nota suficiente para trabalharem naquilo que eles querem. Que é importante se eles querem ter futuro têm que começar por aí, pelo menos na minha perspectiva penso assim, não é ?" (Braga)

"O povo cigano está limitado ao negócio da feira e da venda ambulante, praticamente mais nada, e se houvesse outras alternativas seria bom." (Vila Quatro Olhos, Porto).

Como evidencia um estudo realizado pelo Secretariado Diocesano da Pastoral dos Ciganos (Reis; 1999), a noção do declínio da venda estará porventura na base de uma nova postura dos ciganos mais jovens face ao mercado de emprego. Nesse estudo, $77 \%$ dos 200 jovens inquiridos, entre os 16 e os 25 anos de idade, afirma ter interesse em frequentar cursos de formação profissional (Reis, 1999). Mesmo que se tenha em conta a possibilidade de nele existir um efeito de enviesamento, associado ao facto de estarem perante uma instituição de cuja intervenção são beneficiários, o que poderia trazer um ênfase nas respostas que pensam ser as esperadas, existem alguns indícios que confirmam aquele dado.

Um desses indícios diz respeito às razões daqueles que se sentiam apenas "razoavelmente satisfeitos" (35\%) e aos que declararam sentir-se "pouco satisfeitos" com a sua profissão (24\%). Destes mais de metade $-62 \%$ e $69 \%$ respectivamente - gostaria de ter outro trabalho.
Se se considerar que $96 \%$ dos inquiridos que declaram exercer actividade são vendedores ambulantes, existem razões para presumir uma disposição favorável a outras profissões.

Analisando as aspirações e projectos dos ciganos entrevistados no estudo que serviu de base para este texto, verifica-se que são apresentadas algumas alternativas à venda. É o caso das entrevistadas do sexo feminino, grupo no qual se encontra uma maior abertura a novas profissões e a outros modos de vida.

Relativamente às aspirações, o corte e costura, os serviços indiferenciados como as limpezas, o ensino e as profissões associadas ao Direito surgem como possibilidades mais recorrentemente referenciadas. Será porventura, importante tomar em consideração que por vezes, estas aspirações são desejos ainda alimentados, outras vezes porém, são exercícios conjecturais, induzidos pelo entrevistador, enunciados sob a condição de não se ser cigana.

"Se não fosse cigana e estudasse, gostava de estudar Direito" (Rio Seco, Lisboa).

Apenas uma cigana que se refere aos seus projectos manifesta a expectativa de manter a venda como actividade profissional, ainda que alterando as condições do seu exercício, isto é, passando a vender numa loja.

Quando interrogadas sobre as áreas de formação que poderiam ser interessantes para a qualificação dos ciganos, cabeleireira, costureira e auxiliar de educação surgem como possibilidades de formação dirigidas a mulheres. Outras áreas que, para as entrevistadas, surgem como vias úteis e interessantes para os ciganos são a construção civil e o turismo (guia turístico). Os homens entrevistados salientam de forma mais vincada que as mulheres, o desejo de continuidade no que diz respeito às suas aspirações pessoais, exprimindo desejos, projectos ou reivindicações de alteração das condições de exercício da actividade da venda, no sentido da sua viabilização. Algumas vezes, essa alteração de condições recai na possibilidade de dispor de um espaço físico, como uma loja ou uma banca, "um lugar certo".

"Se pudesse ter lugar certo, gostava de ter esta profissão (...) Quero uma banca, só isso" (Bairro da Buraca, Lisboa) 
Outras, é simplesmente, o desejo de deter meios para desenvolver a actividade de forma mais próspera.

"Eu gostava de ter uma casa, uma casa decente (...) muito dinheiro para ir para as feiras... para sair da miséria, não passar fome, isso é que era bom. Era bom, era bom que nos desse o dinheirinho para nós viver assim... e ir para as feiras, comprar muito material, isso é que era bom." (Vila Verde, Braga).

De entre os seis homens que se manifestaram relativamente a projectos ou aspirações profissionais, três referiram-se a outras profissões que não a venda. A idade não parece aqui uma variável relevante na explicação da maior ou menor abertura a actividades para além da venda, uma vez que estando grande parte dos entrevistados na faixa dos trinta, isto é, numa faixa etária relativamente jovem, foi também entre aqueles que tinham cerca de vinte anos manifesto o desejo de continuar na actividade das vendas.

Deparámo-nos com informações que de algum modo, divergem daqueles recolhidos pela SNPC no sentido em que não parece ser a idade que explica as diferenças entre atitudes face à vida profissional. Níveis mais elevados de escolaridade e a experiência de exercício de outras actividades parecem prevalecer como factores explicativos da abertura a novas áreas profissionais, já que são os dois monitores de formação e o mediador que enunciam projectos de actividade alternativos à venda. Seria pois, a existência de intervenção junto de determinados indivíduos ou comunidades - factor presente na população entrevistada por aquele organismo - a explicar essa abertura.

Exceptuando estes três casos, a opção por outras profissões é, para a maior parte dos ciganos entrevistados, uma "segunda escolha" motivada por constrangimentos exteriores à sua vontade que determinam o declínio da venda ambulante tal qual os ciganos a praticam.

No que diz respeito às diferenças de género mais uma vez, a pesquisa empírica aconselha cautela relativamente ao "primado epistemológico" da pertença étnica sobre todas as outras pertenças" subjacente a uma perspectiva multiculturalista (Machado, 1999). De facto, o papel mais subalternizado da mulher no que diz respeito à actividade económica e a maior insatisfação com o seu estatuto, poderão ser eventuais explicações para esta diferença de projectos e aspirações. De facto, ainda que sejam elas a ter o papel principal na venda, não existe de facto muita autonomia no que diz respeito às escolhas profissionais (Câmara Municipal de Coimbra, 2005).

Finalmente, analisando as expectativas e projectos expressos pelos entrevistados relativamente às escolhas face ao futuro dos filhos, verifica-se não só, uma valorização discursiva da escola que aparece em todos os testemunhos, como, recorrentemente, o desejo que o percurso dos filhos não passe pela venda, mas "por um trabalho próprio".

"Não sei, para já não tenho, não estou a pensar nisso, mas olha ao gosto deles crescerem, ao gosto deles, mas os estudos vão ir até ao fim, isso sem dúvida nenhuma." (Braga).

"Estou a fazer para ser melhor [o futuro dos filhos], para ele ter um curso, não quero que venda, quero que estude..." (Bairro da Buraca, Lisboa)

"Se os meus filhos tivessem estudado e eu pudesse, eu queria os meus filhos empregados em qualquer emprego, só que eles também mandam." (Casalinho da Ajuda, Lisboa)

"A vida dos ciganos é esta, nem todos os ciganos, alguns ciganos têm trabalho próprio, trabalho e eu espero que os meus filhos tivessem um trabalho próprio para ganharem a vida, para manter a casa deles, que eu sei que o curso deles, o curso que eles estão a fazer que..." (Prado, Braga).

"Adorava que os meus netos continuassem a estudar para apanhar um bom emprego, porque a vida de cigana de aqui para a frente não deve ser muito boa, gostava que tivessem um futurozinho para eles." (Évora).

Apenas num dos casos, o pai assume que prefere que os filhos sigam as trajectórias tradicionais entre os ciganos, ainda que equacionar a situação contrária não parece perturbá-lo muito.

"Espero que eles continuem sempre a fazer as mesmas coisas, a seguir as mesmas regras, mas se fugirem às regras é igual." (Évora).

Relativamente às aspirações para a nova geração dirigidas especificamente às áreas profissionais, elas variam entre uma actividade alternativa ainda que frequentemente pouco definida - "trabalhar" em vez de vender; tirar um curso - e as profissões intelectuais e científicas como advogado ("grandes advogados"), professor ("grandes professores") e engenheiro. 
"Sim, mas não digo que o meu filho quando mais tarde trabalhar não estude, se o meu filho quiser. Mas se continuassem a estudar e se quisessem trabalhar não me importava, há ciganos a trabalhar... Não sei, não sei [qual a profissão que gostaria que os filhos tivessem]" (Bairro S. João de Deus, Porto).

"Depois a mentalidade deles está preparada para os ciganos de agora, pronto, eles não querem vender, até aí está tudo bem, a menina diz 'Oh mãe, eu quero ser, quando for grande quero ser advogada' e eu disse 'Isso é bom'." (Lisboa).

"Gostava, gostava... [que seguissem até Ensino Superior] Grandes professores, grandes médicos, não é? Gostava que elas fossem... não é?" (Vila Verde, Braga).

"Gostava muito que o meu neto mais velho fosse ou engenheiro ou advogado. (Évora).

$\mathrm{O}$ desdobramento das atitudes face aos percursos profissionais dos ciganos expressos através das expectativas face à formação profissional, atitudes face à situação profissional do próprio, em avaliações do papel da venda entre os ciganos e projectos e aspirações profissionais para si e para os filhos e netos, revela um quadro complexo relativamente à relação que os ciganos mantêm com as actividades tradicionalmente exercidas e com o modo de vida que lhes está inerente. De facto, seria difícil manter os enunciados de Formoso e de Liégeois, já que o "emprego" e o "trabalho" aparecem de uma forma vincada no discurso dos ciganos, quando se referem ao futuro da nova geração, conotados com melhores condições de vida ${ }^{24}$.

Também se poderia concluir que existe alguma abertura a novas áreas profissionais, decorrente de uma análise pessimista do futuro da venda e uma apreciação mais negativa que positiva do tipo de vida que ela implica e proporciona. Contudo, não deixa de ser reveladora a prevalência de projectos e aspirações pessoais de âmbito profissional em que é manifestado o desejo de melhoria das condições de exercício da venda.

Digamos que existe um registo avaliativo e prospectivo genérico em que a venda aparece condenada à extinção ou pelo menos, não aparece como um meio de vida sustentável. Existe ainda, um re- gisto do "desejável" expresso ao nível do projecto profissional pessoal que evidencia uma inclinação para a continuidade do exercício da venda, ainda que em condições diferenciadas. Esta atitude é tanto mais significativa, quanto se regista entre aqueles que estariam menos condicionados na escolha das suas actividades - os homens (cf. também Câmara Municipal de Coimbra, 2005). Desta forma, dir-se-ia que aqueles que são prevalecentemente os sujeitos da construção dos percursos profissionais entre os ciganos, os homens, são quem aspira para si uma trajectória de continuidade, mesmo quando se pensa nos mais jovens. Em contrapartida, as mulheres, mais marginais na tomada de decisões relativamente à actividade económica não obstante a sua presença mais activa e visível no desempenho das tarefas associadas com a venda, são aquelas que ao nível do discurso mais se distanciam relativamente a esta actividade, talvez por serem sujeitos menos implicados e portanto mais críticos.

\section{Políticas sociais e práticas de inserção: os problemas das soluções}

Para uma reflexão sobre as questões relativas às respostas das políticas sociais e práticas de intervenção que pretendem corrigir dificuldades de parte da população cigana no acesso ao rendimento convirá voltar um pouco atrás reflectindo sobre os seus pressupostos.

O impulso para a criação de respostas específicas para determinados grupos surgiu cerca do início dos anos 80 na Europa com o aparecimento das políticas de inserção. Com elas se reconhecia a necessidade de orientar para públicos particulares, respostas específicas definindo-se por oposição às políticas de integração (Castel, 1998) não só porque obedeciam "a uma lógica de discriminação positiva", intervindo junto de grupos populacionais bem delimitados, mas também porque se sustentavam numa abordagem distinta do papel do estado ${ }^{25}$ e reincorporavam um conjunto de princípios de organização social institucionalizada que tinham sido afastados (Donzelot, 1996).

\footnotetext{
${ }^{24} \mathrm{O}$ estigma associado ao tráfico (e também ao consumo) de drogas entre os ciganos estará provavelmente na base das referências mitigadas que surgem nos discursos surgidos em situação de entrevista. Não obstante este cenário é referido como um elemento novo que de alguma maneira surge como factor de transformações e sobretudo de cisão, é relacionado com rupturas com a tradição que fracturam a comunidade.

${ }_{25}$ Donzelot e Estèbe (1994) desenvolvem a noção de estado animador salientando a necessidade que este tipo de políticas evidenciou de reorganização da forma de actuação pública tradicional.
} 
Tal é o caso da recuperação de elementos prémodernos dos mecanismos de solidariedade traduzidos no retorno do território, do grupo, da etnia enquanto atributos de reforço da semelhança de condições na pertença. A importância dada à noção e à prática da mediação ilustra esta recuperação de concepções do social, afastadas pelo modelo do Estado Providência fordista. A contratualização traduzida na noção de projecto, correspondendo à visão de raiz liberalista do laço social foi ainda recobrada. Em Portugal, esta orientação surge em meados da década de 90, com o modelo do Rendimento Mínimo Garantido, que incorpora o princípio da contratualização mas também com uma orientação de "tipo etnicizante" (Pires, 2003) nas políticas dirigidas à integração dos imigrantes e minorias étnicas que se traduzem para o caso dos ciganos na criação da figura do mediador cultural e no incentivo ao associativismo.

Do ponto de vista da análise dos efeitos das políticas e práticas dirigidas à inversão da situação social dos ciganos em Portugal, as questões colocam-se a vários níveis. Por um lado, e ao nível das políticas sociais temos as que se colocam à leitura da noção de exclusão social subjacente a esses esforços; bem como aquelas que se associam às dificuldades em concretizar as políticas pelo estado português. Existem por outro lado, problemas que se colocam já ao nível das organizações que operacionalizam as medidas e das abordagens utilizadas.

Numa primeira perspectiva, a concepção das políticas, das medidas e dos projectos que nelas se enquadram tem vindo a privilegiar o emprego e a empregabilidade como "variáveis críticas" da promoção da inserção social dos ciganos. Desta forma, foram-se multiplicando iniciativas cujo objectivo é a frequência e aproveitamento de acções de formação por parte da população cigana, com vista à integração no mercado de trabalho. Como foi referido nas entrevistas realizadas, a incidência de casos de insucesso tem sido forte, quer do ponto de vista dos objectivos específicos isto é, a inserção em mercado de trabalho, quer no que diz respeito à finalidade que subjaz a tais objectivos, a inversão das situações de exclusão social.

Deste ponto de vista, e mesmo admitindo transformações culturais importantes nas comuni- dades ciganas, existe um conjunto de desencontros de expectativas que comprometem os objectivos dessas intervenções (cf. também Guerra et al., 2002). Referimo-nos desde logo, ao facto de que se pretendem criar soluções de emprego através do investimento na criação de novas competências, ignorando as já existentes como são as competências associadas às actividades comerciais. Se como se verificou, através das entrevistas, as mulheres manifestam algum desejo de ter outro tipo de ocupação profissional, a venda está ainda bastante presente nos projectos dos ciganos, nos homens sobretudo. Algumas experiências, são alternativas já experimentadas com sucesso incidindo, no apoio à constituição de pequenos negócios através da disponibilização de capital para investimento, da formulação de currículos formativos orientados para o aprofundamento de competências de gestão, de conhecimento dos procedimentos e instrumentos necessários ao lançamento e à gestão de pequenas iniciativas comerciais, como a organização da contabilidade em que simultaneamente se procura promover a cidadania através do incentivo à legalização das actividades e pagamento das contribuições (Castro, Marques, 2000). Trata-se aqui de assumir um modelo de cidadania enquanto conjunto de direitos e deveres, por referência aos quais se propõe a inversão das situações de precariedade dos ciganos, por contrapartida à prescrição de um modelo de integração com base no assalariamento em actividades para as quais normalmente os visados não estão predispostos.

Esta opção que tem vindo a ser repetida em sucessivos projectos de formação, poderá ter resultados negativos, sob várias perspectivas. Por um lado, pode questionar-se a sua eficácia, uma vez que acaba por encontrar resistências por parte dos próprios ciganos. Muitas vezes essa resistência é tácita e tem como resultado a criação dos "profissionais da formação" que aceitam as propostas dos técnicos, como contrapartida de um benefício, mas sem qualquer predisposição para dar um prosseguimento consequente à trajectória visionada na concepção deste modelo de intervenção de que o técnico é o mediador (Guerra et al., 2002). Este tipo de propostas baseiam-se na representação de que a exclusão se combate através da sequência representada no esquema da página seguinte: 


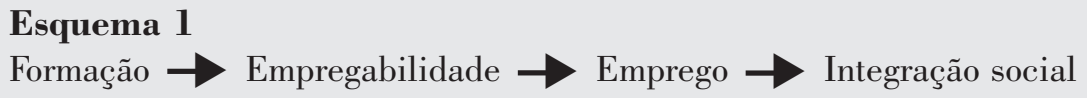

Logo:

Esquema 2

Formação $\rightarrow$ Integração social

Por outro lado, a recuperação da noção de contratualização que acompanhou a introdução das políticas de inserção ou das "políticas sociais activas" e no caso português teve expressão nos acordos de inserção do Rendimento Mínimo Garantido tem um conjunto de pressupostos. O princípio de contratualização supõe a adequação do projecto a expectativas do indivíduo a quem é proposto um determinado percurso de inserção, condição que nem sempre se cumpre. Esta falha resulta da preponderância simbólica dos discursos técnicos dada a desigualdade de posições, de recursos materiais, discursivos e de poder nas situações de contratualização.

Estes problemas são agravados em Portugal, por insuficiências importantes ao nível da implementação das políticas de inserção no que diz respeito à reorganização do estado, no sentido em que não são criadas condições para que medidas como o RMG (posteriormente Rendimento Social de Inserção), disponham de recursos técnicos para garantir o apoio continuado aos projectos de inserção propostos, condição fundamental para fazer ajustes previstos pela medida.

Naquilo que diz respeito à concepção dos projectos no terreno, existem também debilidades no que diz respeito às metodologias utilizadas para levar a cabo a oferta formativa existente. Os representantes de instituições com trabalho directo junto da população entrevistados evidenciaram a sua desadequação à população cigana (como a outras populações desfavorecidas) na medida em que se recorre a modelos demasiado escolares, sobretudo no que diz respeito aos instrumentos pouco adaptados a populações com baixos níveis de qualificações.
Os insucessos, sublinhados por alguns dos nossos entrevistados institucionais, devem-se ainda a factores que afectam de modo geral, todas as categorias de beneficiários das acções de inserção socioprofissional e estão associadas a debilidades ao nível dos agentes que operacionalizam os programas e medidas. A precariedade dos projectos, a falta de preparação de dirigentes (cf. também Capucha et al., 1995) ou o isolamento de técnicos e as debilidades que sentem quer ao nível das metodologias, quer ao nível do domínio dos instrumentos legais existentes ${ }^{26}$, são algumas das deficiências que o trabalho com estas populações denota, como nos confirmaram as entrevistas com os técnicos e responsáveis auscultados no curso deste estudo. O "abandono" a que são deixadas as pessoas a partir do momento em que fica estabelecido qualquer tipo de vínculo, mesmo que precário, com uma entidade contratante quer devido a insuficiências de concepção dos modelos de inserção, quer devido à exiguidade de recursos, são outros dos factores importantes para compreender tais insucessos frisados pelos entrevistados e já evidenciados noutros trabalhos (Castro et al., 2000).

Acrescente-se ainda, alguns problemas de sustentabilidade das alternativas de acesso ao rendimento que remetem para a precariedade dos empregos onde se faz a integração dos formandos que chegam ao final das acções de formação e do seu período de estágio. Desta forma, este tipo de solução não constitui alternativa para a satisfação de expectativas padronizadas na sociedade portuguesa e progressivamente incorporadas pelas comunidades ciganas, também ainda que não só, como resultado do trabalho social.

\footnotetext{
${ }^{26}$ Existe um efeito paradoxal no aparelho normativo e legislativo português na área do emprego e da empregabilidade que consiste na coexistência de uma abundância legislativa e da multiplicação de medidas, com uma eficácia reduzida da sua implementação que decorre quer da inadequação da operacionalização de tais medidas e políticas, quer do desconhecimento que os próprios técnicos que trabalham nesta área têm relativamente à sua existência, tão grande é o seu número e deficiente a sua divulgação.
} 
Este é um problema que não se coloca só ao nível das inserções no sector empresarial mas também relativamente a outras respostas no âmbito do mercado social de emprego como os cursos de mediadores culturais ministrados por várias organizações que trabalham com a população cigana. Tais iniciativas que muitas vezes conduzem a experiências bem sucedidas e interessantes do ponto de vista das instituições, das populações abrangidas e dos próprios mediadores, não têm garantido alternativas viáveis às actividades tradicionais dos ciganos, já que durante muito tempo não esteve reconhecido o estatuto do mediador cultural e se mantém a precariedade que marca os seus vínculos institucionais.

A fraca sustentabilidade das respostas propostas, a par com o esvaziamento de referências resultante de uma desvalorização implícita ou explícita das competências e modos de vida tradicionais dos ciganos, pode criar entre estas comunidades ausências em termos de referências e de rupturas na coesão destes grupos, de algum modo semelhantes aos que se pretende combater entre os jovens imigrantes africanos de segunda geração.

Não queremos ao nível das soluções políticas aderir à perspectiva multiculturalista em que a hipervalorização da identidade cultural "elimina a liberdade individual conduzindo em última instância ao "direito à servidão" como refere Machado (1999) citando Alain Finkielkraut (1988), nem defender um modelo de intervenção que confine os grupos a um leque restrito de possibilidades. De modo nenhum se trata de olhar os ciganos como membros de uma cultura irredutível e estática.

Trata-se sim de assumir diferenças resultantes não só da vulnerabilidade deste grupo às desigualdades criadas pela negação do benefício efec- tivo de um conjunto de direitos que o modelo de desenvolvimento português impôs a parte significativa da população portuguesa, mas também de modelos de organização e traços culturais que configuram dinâmicas de subjectividade contrastantes com as de grande parte da sociedade portuguesa que os efeitos de quadros jurídicos e/ou práticas discriminatórias foram cristalizando em razão de mecanismos de fechamentos das comunidades ciganas.

Este reconhecimento resulta assim, não na reivindicação de medidas específicas ou na vinculação das soluções propostas aos ciganos a práticas ancestrais independentemente das questões que se coloquem do ponto de vista do tratamento igualitário dos cidadãos perante a lei ou da liberdade individual. Trata-se de defender um entendimento mais alargado da noção de integração social que não associe a pertença a uma sociedade a um modelo salarial de inserção social.

Referenciar a noção de integração e de exclusão respectivamente ao benefício de um conjunto de direitos que correspondem a consensos reconhecidos pelas sociedades e à ausência dele permite um entendimento destas noções que inclua a "pluralidade vasta, aberta e mutável de estilos de vida, todos partilhando a cidadania" (Almeida, 1993: 830). Julga-se que as virtualidades deste entendimento de exclusão consistem por um lado em contributos para o entendimento das situações como as que são vividas por parte dos ciganos em Portugal, e por outro, em orientações ao nível das práticas com vista à promoção da integração social que permitam um quadro mais largo de soluções para a inserção dos ciganos que não prescinda nem dos referenciais normativos básicos vigentes na sociedade portuguesa. 


\section{Bibliografia}

ALBUQUERQUE, José, BOMBA, Teresa, 2001, "Pobreza e condições de vida em Portugal" in Como está a Economia Portuguesa?, IV Conferência Sobre Economia Portuguesa, Lisboa, CISEP

ALBUQUERQUE, José, e BOMBA, Teresa, MATIAS, Isabel, Rodrigues, Carlos Farinha, Matos, Gisela, 2002, "Distribuição de Rendimentos e Condições de Vida" in Portugal 1995-2000: Perspectivas de Evolução Social, Oeiras, DEPP/ MTS e Celta Editora.

ALMEIDA, João Ferreira de, 1993, "Integração social e exclusão social: algumas questões", Análise Social, Número 123-124, Volume XXVIII, Lisboa, pp. 829- 834.

ALMEIDA, João Ferreira de, 1986, Classes Sociais nos Campos: Camponeses Parciais numa Região do Noroeste, Coleccão Teses e Teorias, Lisboa, Edições do Instituto de Ciências Sociais da Universidade de Lisboa.

BERGHAM, Jos, 1995, "Social exclusion in Europe: policy context and analytical framework" in ROOM, Graham (org.), Beyond the Threshold: the Measurement and Analysis of Social Exclusion, The Policy Press, Bristol, pp. 10-28.

BJORKLUND, Ulf, 1987, "Ethnicité et état providence" Revue International des Sciences Sociales, n. $^{\circ} 111$.

BOURDIEU, Pierre, 1979, La distinction: Critique Sociale du Jugement, Paris, Editions de Minuit.

BRUTO DA COSTA, Alfredo, ANDERSON, J., CHIGOT, C., DUFFY, K., MANCHO, S., \& MERNAGH, M, 1994, Contribution of the 'Poverty 3' programme to the understanding of poverty, exclusion and integration, Lille, Animation et Recherche.

CÂMARA MUNICIPAL DE COIMBRA, 2005, Coimbra, Cidade de Todos. Projecto Equal - Diagnóstico de Necessidades, Texto Policopiado.

CAPUCHA, Luís et al., 1995, ONG's de Solidariedade Social: Práticas e disposições, Cadernos REAPN, REAPN/Portugal.

CAPUCHA, Luís, 1998a, "Exclusão e acesso ao emprego: paralelas que podem convergir" Sociedade e Trabalho, Lisboa, DEPP, Ministério do Trabalho e Solidariedade.

CAPUCHA, Luís, 1998b, "Pobreza, Exclusão e Marginalidades" in Portugal, que modernidade?, Oeiras, Celta Editora.

CAPUCHA, Luís, 2000, “Nós e eles cá dentro: sobre o mito de um Robinson Crusoe ao contrário", in Pobreza, Exclusão: Horizontes de Intervenção, Imprensa Nacional - Casa da Moeda, Lisboa

CASTEL, Robert, 1998, As Metamorfoses da Questão Social, Editora Vozes, Petrópolis.

CASTRO, Alexandra, 1994, Apropriação do Espaço e Estratégias Identitárias do Grupo Étnico Cigano no Bairro da Malagueira, Tese de Licenciatura em Sociologia, Lisboa, Instituto Superior de Ciências do Trabalho e da Empresa.
CASTRO, Alexandra, 1995, "Ciganos e habitat: entre a itinerância e a fixação" Sociologia: Problemas e Práticas, n. ${ }^{\circ} 17$, pp. $97-111$.

CASTRO, Alexandra, 2002, Caracterização dos Perfis dos Beneficiários RMG: Minorias Étnicas, Avaliação de Impactes do Rendimento Mínimo Garantido, Beneficiários. Histórias de Vida, Lisboa, Instituto para o Desenvolvimento Social.

CASTRO, José, MARQUES, Sofia, 2000, Modelos de Formação e Inserção Socio-Profissional de Pessoas Desfavorecidas: Dimensões e Tipologia: Boas Práticas, Acção Modelar, Projecto SIFAT, Iniciativa Emprego/Eixo Integra, Porto, REAPN/ /Portugal.

COSTA-LASCOUX, Jacqueline,1996, "Immigration: de l'exil à l'exclusion?" in Serge Paugam (org.), L'Exclusion: L'État des savoirs, Paris, Éditions La Découverte.

DIAS, Eduardo Costa (coord.) et al., 2001, A Comunidade Cigana em Portugal: Representações e Dinâmicas de Exclusão/Integração, CIES, REAPN/Portugal, Secretariado Diocesano para a Pastoral dos Ciganos, Programa de Promoção Social dos Ciganos, policopiado.

DONZELOT, Jacques, 1996, "Les transformations de l'intervention sociale face à l'exclusion" in Serge Paugam (org.), L'Exclusion: L'État des savoirs, Paris, Éditions La Découverte.

DONZELOT, Jacques, ESTEBE, Philippe, 1994, L'État Animateur: Essais sur la politique de la ville, Ville et Société, Paris, Éditions Esprit.

GUERRA, Isabel, LOPES, Elisabete, AMOR, Teresa, 2002, Caracterização dos Perfis dos Beneficiários RMG: Minorias Étnicas, Avaliação de Impactes do Rendimento Mínimo Garantido, Lisboa, Instituto para o Desenvolvimento Social.

LENOIR, René, 1974, Les exclus, un Français sur Dix, Paris, Seuil.

LIÉGEOIS, Jean-Pierre, 1989, Ciganos e Itinerantes, Santa Casa da Misericórdia, Lisboa.

MACHADO, Fernando Luís,1991, Etnicidade em Portugal: Aproximação ao Caso Guineense, Provas de Aptidão Pedagógica e Capacidade Científica, 1992, ISCTE, Lisboa, policopiado.

MACHADO, Fernando Luís, 1999, Contrastes e Continuidades: Migração, Etnicidade e Integração dos Guineenses em Portugal, Tese de Doutoramento em Sociologia, Lisboa, ISCTE, policopiada.

MACHADO, Paulo, 1994, "A presença cigana em Portugal: um caso de exclusão secular" Revista Mediterrâneo, n. ${ }^{\circ} 4$, Jan.Jul.

MARQUES, Cesarina, CORREIA, Joaquina Rosa, Reis, Maria Fernanda, 1997, Comunidade Cigana na Diocese de Lisboa, Lisboa, Secretariado Diocesano de Lisboa Obra Nacional para a Pastoral dos Ciganos/Departamento de Acção Social da Câmara Municipal de Lisboa.

MENDES, Maria Manuela Ferreira, 2005, Nós, os ciganos e os outros. Etnicidade e exclusão social, Lisboa, Livros Horizonte. 
MERRIEN, François-Xavier, 1996, "État providence et lutte contre l'exclusion" in PAUGAM, Serge (org.), L'Exclusion: L'État des Savoirs, Paris, Éditions La Découverte.

OKELY, Judith,1983, The Traveller-Gypsies, Cambridge, University Press.

PAUGAM, Serge, 1996, (org.), L'Exclusion: L'État des Savoirs, Paris, Éditions La Découverte.

PINTO, Maria de Fátima, 2000, A Cigarra e a Formiga: Contributos para a reflexão sobre o entrosamento da minoria étnica cigana na Sociedade Portuguesa, Cadernos REAPN, Porto, REAPN.

PIRES, Rui Pena, 2003, Migrações e Integração, Oeiras Celta.

REIS, Fernanda, 1999, O Jovem Cigano e a Formação: Atitudes e perspectivas frente ao Mundo do Trabalho, Secretariado Nacional da Pastoral dos Ciganos, Lisboa.
ROOM, Graham et al., 1992, Observatory on National Policies to Combat Social Exclusion. Second Annual Report. Report to the Commission of the European Communities, Lille, European Economic Interest Group, Animation and Research.

ROOM, Graham,1995, "Poverty and social exclusion: the new european agenda for policy and research" in ROOM, Graham (org.), Beyond the Threshold: the Measurement and Analysis of Social Exclusion, The Policy Press, Bristol, pp. 1-9.

SCHNAPPER, Dominique, 1996, "Intégration et exclusion dans les sociétés modernes" in PAUGAM, Serge (org.), L'Exclusion: L'État des Savoirs, Paris, Éditions La Découverte.

SILVA, Pedro Adão,1998, "O Rendimento Mínimo Garantido e a nova questão social" Sociedade e Trabalho, n. ${ }^{\circ} 3$, pp. 34-49. 